\title{
LOS ORÍGENES DEL PLEITO DEL OBISPADO DE ORIHUELA (SIGLOS XIII-XIV)
}

\author{
Antonio CARRASCO RODRÍGUEZ
}

Universidad de Alicante

En 1243, el infante D. Alfonso -en representación de su padre Fernando III el Santo- y el emir murciano Ibn Hud pactaron en Alcaraz el protectorado castellano sobre las tierras del antiguo reino hudita.

La ocupación de este territorio propició el encuentro de los castellanos con los catalano-aragoneses de Jaime I. Por ello, la revisión de los acuerdos de Tudillén y Cazola se plasmó en 1244 en el tratado de Almizra, en el que se redefinieron las áreas de influencia y conquista de ambas potencias, quedando las tierras del sur de la actual provincia de Alicante en territorio castellano.

$Y$ de inmediato, D. Alfonso asumió la tarea de reorganizar las tierras recién conquistadas. Así, desde el punto de vista espiritual, planteó la necesidad de restaurar la antigua sede episcopal cartaginense. Sus deseos gozaron de una acogida muy favorable en Roma, pero toparon con los intereses de Jaime I, quien antes de emprender su labor reconquistadora, había prometido a los catalanes restituir el obispado de Valencia a la jurisdicción del metropolitano tarraconense y las tierras comprendidas entre Denia y Orihuela a la del prelado de Barcelona'. El asunto se complicó aún más cuando las sedes de Toledo y Tarragona reclamaron para sí la sufraganeidad de la futura diócesis de Cartagena.

Al fin, las repetidas instancias del primogénito castellano surtieron efecto, de modo

1 VILAR, J.B., Orihuela musulmana. Historia de la ciudad de Orihuela, t. II, Murcia, 1976, p. 131. Las citadas tierras pertenecían a la jurisdicción eclesiástica de la mitra de Barcelona en virtud de un acuerdo suscrito en el año 1058 por Alí ibn Muyahid, emir de Denia y señor de las Baleares, con Ramón Berenguer I. En él, el conde-marqués catalán reconocía solemnemente a Alí como soberano de Denia y las Baleares; y a cambio, el musulmán facultaba al prelado barcelonés para ordenar a los obispos, proveer los demás cargos eclesiásticos, y entender en el gobierno y dirección de tales iglesias. 
que Inocencio IV, el 31 de julio de 1250, decretó el restablecimiento de la sede cartaginense, y poco después, el 6 de agosto siguiente, propuso una fórmula de compromiso a la cuestión de la sufraganeidad, declararla exenta, esto es, directamente dependiente de la Santa Sede? 2 .

Durante los años transcurridos entre el acuerdo de Alcaraz y la muerte de Ibn Hud hacia 1259, la totalidad del emirato, que había aceptado el protectorado castellano, vivió en una situación de precario equilibrio político. No obstante, tras el fallecimiento del emir y aprovechando el rompimiendo de Granada con Castilla, en 1264, los mudéjares murcianos, confabulados con nazaríes y norteafricanos, se sublevaron contra el dominio cristiano. Ocupado el ya rey Alfonso X el Sabio en combatir la sedición andaluza, no tuvo más opción que solicitar la ayuda de Jaime I para sofocar la insurrección murciana. Tras ordenar una primera intervención a su hijo Pedro, en noviembre de 1265 se puso al frente de un gran ejército y emprendió la marcha hacia el sur. No halló gran oposición en las tierras alicantinas de modo que en enero del año siguiente pudo iniciar el sitio de la ciudad de Murcia, que se rindió el 2 de febrero. Así, tras aplastar la rebelión y asentar en el reino murciano a algunos repobladores catalanes y aragoneses, lo devolvió a Alfonso $\mathrm{X}$, sin que en nada se modificasen las líneas de frontera civiles y eclesiásticas ${ }^{3}$.

Años más tarde, bajo el episcopado de Diego Martínez Magaz, asistimos al primer suceso relevante de la iglesia de Orihuela tras la dominación musulmana; un hecho que, al fin y al cabo, constituiría la base prístina de las futuras aspiraciones episcopales de la población del Bajo Segura. Por real privilegio dado en Córdoba el 27 de mayo de 1281, Alfonso X estableció que la iglesia de El Salvador y Santa María fuese la mayor de la villa - la iglesia arciprestal- y tuviese, por tanto, primacía sobre las demás parroquias o «collaçiones»" .

Asimismo, hemos de destacar también al obispo Magaz porque fue el principal impulsor de la traslación de la sede episcopal de Cartagena a Murcia. Los motivos aducidos por el prelado y el cabildo cartaginenses eran fundamentalmente pastorales. La hasta entonces sede episcopal, por su situación costera, sufría continuas agresiones de los sarracenos. Y, además, se hallaba aislada del resto de la diócesis, ya que el campo y los caminos entre dicha ciudad y la sierra de Carrascoy se hallaban infestados de ladrones que dificultaban un acceso seguro a ella. Se hacía, por tanto, necesaria para la atención espiritual de los feligreses la traslación de la sede episcopal a otra ciudad, que fuera populosa e insigne, que se hallase en una mejor ubicación espacial dentro de la diócesis, y que ofreciese mejores vías de comunicación. Obviamente, la ciudad elegida tenía que ser Murcia. Las primeras instancias del prelado y el capítulo fueron dirigidas al pontífice Nicolás III, pero sus peticiones no tuvieron el resultado apetecido hasta que una bula de Nicolás IV, dada el 13 de septiembre de

2 ALDEA, Q. y otros, Diccionario de Historia Eclesiástica de España, Madrid, 1972, p. 998.

3 Todos estos hechos son narrados con detalle por BALLESTEROS-BERETTA, A., Alfonso $X$ el Sabio, Barcelona, 1963, pp. 388-403, y también por VILAR, J.B., op. cit., pp. 199-206.

4 Archivo Municipal de Orihuela, Libro Becerro de Privilegios Reales. También es citado en GISBERT Y BALLESTEROS, E., Historia de Orihuela, t. I, Orihuela, 1901, pp. 493-495. 
1289, decretó la traslación. Ésta fue aprobada por el rey Sancho IV el Bravo en dos cartas fechadas el 26 y el 29 de mayo de $1291^{5}$.

Con toda seguridad, la noticia no debió caer muy bien en Orihuela, puesto que a partir de entonces, Murcia, su enemiga capital desde tiempo inmemorial, pasaba a ser la sede del obispado, y a ella habrían de acudir los oriolanos a solucionar sus cuestiones de orden eclesiástico ${ }^{6}$.

El 25 de abril de 1295 falleció en Toledo el monarca castellano Sancho IV. Y pese a que en su testamento, con claridad, había señalado como heredero a su primogénito Fernando - menor de edad-, y a su mujer, María de Molina, le había encargado la gobernación del reino, su sucesión no fue tan sencilla. El matrimonio del rey Sancho IV y María de Molina, ilícito por razón de parentesco, no había sido reconocido por la Santa Sede, por lo que la condición de bastardo de Fernando lo incapacitaba para reinar. Por ello, los infantes de la Cerda -Alfonso y Juan-, que se hallaban en Aragón, reclamaron para sí la corona castellana.

Alfonso de la Cerda y Jaime II el Justo de Aragón firmaron un acuerdo en Bordalva, el 21 de enero de 1296. En él, el rey aragonés se comprometía a ayudar al infante en su guerra contra Fernando IV el Emplazado. A cambio se concertó la cesión a la Corona de Aragón del Reino de Murcia, del cual formaba parte, como sabemos, la ciudad de Orihuela y el sur de la actual provincia de Alicante ${ }^{7}$. La coalición contaba además con el apoyo de los musulmanes granadinos, del rey Dionís de Portugal, y del rey de Navarra Felipe IV, todos los cuales tenían problemas fronterizos con Castilla.

En cumplimiento de lo pactado, Jaime II marchó con un gran ejército hacia tierras levantinas. Tomó diversas plazas, entre ellas Alicante y Orihuela, cuyos habitantes le prestaron juramento de sumisión y homenaje en la iglesia arciprestal el 11 de mayo ${ }^{8}$.

5 DÍAZ CASSOU, P., Serie de los obispos de Cartagena, Madrid, 1895, pp. 22-25. FITA, F., «La Catedral de Murcia en 1291» y «Bosquejo histórico de la sede Cartaginense, por el obispo D. Diego de Comontes", en Boletín de la Real Academia de la Historia, t. III, cuad. 5 (1883), pp. 268-275 y 276 293. GISBERT Y BALLESTEROS, E., op. cit., t. I, pp. 525-527.

6 VILAR, J.B., op. cit., pp. 69-70 nos muestra el origen de esa enemistad capital. Hacia el año 825, Abd al Rahman II hubo de hacer frente a una de las frecuentes contiendas tribales que enfrentaban a yemeníes y sirios en la cora de Tudmir. Tras derrotar a los sediciosos y para prevenir futuras discordias, pensó en trasladar los organismos administrativos de la cora - que se hallaban repartidos entre Orihuela y Hellín - a una nueva ciudad fundada por él, que, situada en las inmediaciones de la urbe orcelitana, en adelante la desplazaría como capital de la región. La citada ciudad, a la que no faltaban algunos precedentes prerromanos, recibió el nombre de Murcia —Mursiya- En el 831, la ciudad estaba ya construida y en ella se instaló, por orden del emir, el gobernador Ibn Labid.

7 Tenemos constancia de tal donación gracias a una carta dada en Serón (Soria) el 3 de febrero de 1296 por el propio Alfonso de la Cerda para Jaime II de Aragón que se halla en el Archivo Municipal de Orihuela, Libro Becerro de Privilegios Reales, f. 9v-10, publicada por MARTÍNEZ MORELLÁ, V., Cartas de los reyes de Castilla a Orihuela, 1265-1295, Alicante, 1954, p. 87; también aparece en TORRES FONTES, J., Colección de Documentos para la Historia del Reino de Murcia, II, Murcia, 1969, pp. 118-119,

8 Archivo Municipal de Orihuela, Libro Becerro de Privilegios Reales, f. 15-16v, publicada por TORRES FONTES, J., op. cit., $\mathrm{n}^{\circ}$ CXX, p. 122; y por ESTAL, J.M. del, “Nuevos datos sobre el asedio y conquista de Orihuela por Jaime II de Aragón', en Revista del C.E.U. de Alicante, 2 (1977), pp. 99-109. 
Después se adueñó de prácticamente todos los lugares, poblaciones y castillos del reino de Murcia. Y por fin, el 12 de agosto se apoderó de la capital de este reino.

Pero en 1301 fueron legitimados los hijos de María de Molina, con lo que Alfonso de la Cerda perdió su condición de pretendiente a la Corona de Castilla, y Jaime II el pretexto para su intervención.

La amenaza de sublevación de los unionistas aragoneses y el afianzamiento del poder de María de Molina, que logró apartar de la coalición a los monarcas de Portugal y Navarra, a los musulmanes y al infante Juan de la Cerda, aconsejaron al rey aragonés entablar negociaciones con Castilla.

Dada la multitud de intereses creados y de partes afectadas se hizo necesaria la intervención de tres árbitros. Por Castilla fue designado el infante D. Juan Manuel - hijo de Alfonso X-; por la Corona de Aragón, D. Ximeno de Lema —prelado de Zaragoza-; y como mediador entre ambos, D. Dionís — rey de Portugal—. Y el 8 de agosto de 1304, en Torrellas - cerca de Tarazona - sentenciaron por vía de compromiso que Cartagena, Guardamar, Alicante, Elche — con su puerto de mar y todos los lugares cercanos-, Elda, Novelda y Orihuela —con todos su términos-, pertenecieran en adelante a la Corona de Aragón; que Murcia, Molina, Monteagudo, Alhama y Lorca, y los demás términos y lugares del reino de Murcia fuesen restituidos a la monarquía castellana; y que el señorío de Villena quedase en propiedad del infante D. Juan Manuel. Y para que el convenio tuviese validez, el día siguiente ambos reyes -Fernando IV y Jaime II- lo ratificaron en Campillo?.

Aunque se hizo la paz entre ambas coronas, no quedó solucionado el asunto. El 26 de febrero de 1305 los dos monarcas se reunieron en el monasterio cisterciense de Huerta. En la entrevista, Jaime II propuso ceder graciosamente Cartagena a Castilla a condición de que Fernando IV diese la villa de Alarcón a D. Juan -el hijo de D. Juan Manuel-.

Y después, para la ejecución del fallo arbitral, fueron nombrados comisarios Diego García de Toledo — privado del rey de Castilla - y Gonzalo García — miembro del Consejo Real de Aragón-. Las negociaciones se celebraron en Elche y tuvieron su desenlace el 19 de marzo de ese mismo año. El acta de avenencia y partición hizo más precisas las líneas de frontera, y situó el límite entre los reinos de Valencia y Murcia en las poblaciones del Pilar de la Horadada y San Pedro del Pinatar respectivamente. $Y$ una vez que fue aprobada por los dos monarcas el 6 de diciembre del mencionado año, se hizo efectiva la nueva delimitación de los términos de Orihuela y Murcia y, por consiguiente, de las Coronas de Castilla y Aragón ${ }^{10}$.

La incorporación formal de los nuevos territorios se produjo bajo la nueva denomi-

9 En el Archivo de la Catedral de Orihuela, Actas Capitulares, Libro II, «Copia del proces de la Cathredal de la Esglesia de Oriola", ff. 208v-214v, hallamos copias de la Sentencias Arbitrales de Torrellas y de Elche realizadas por Francisco Vilanova, notario y escribano de la Sala del Magnífico Consell de la ciudad de Orihuela. J.M. del ESTAL analiza ambos fallos arbitrales en El Reino de Murcia bajo Aragón (1296-1304/5). Colección de Documentos Medievales Alicantinos. 1/1, Alicante, 1985, pp. 89-103.

10 GISBERT Y BALLESTEROS, E., op. cit., t. II, pp. 15-19. 
nación administrativa de Reino de Valencia ultra Sexonam. El gobierno se encargó a un Ilochtinent de Procurador, y para la gestión económica se creó la Bailía General de Orihuela, población en la que se fijó la capital de la Procuración ${ }^{11}$.

Un informe del capítulo de El Salvador, presentado el 5 de octubre de 1525 por el síndico Gil Gómez al gobernador del reino de Valencia más allá de Jijona, D. Pedro Maza de Lizana, evidencia de una manera tan sencilla como clara cómo ambas ciuda'des quedaron fronterizas, y con diferentes lenguas y opiniones: «per ço los de Murcia parlen castella e los de Oriola valencia los uns se nomenen castellans los altres valencians los uns son de la Corona Real de Castella los altres de la Corona Real de Arago tots vasalls de S. M. empero regits e governats ab diverses leys furs e privilegis pratiques e costums en la ciutat de Murcia esta lo port de Castella hon hi paguen los drets de moxariffat aduanes e altres drets reales los quals fan pagar als de Oriola entrant y exint en la dita ciutat de Murcia y per lo semblant en Oriola esta la taula dels drets reals del Regne de Valencia per als que van a Murcia". Y también el cariz de sus relaciones a partir de las sentencias de Torrellas y Elche: «entrant los uns en lo terme dels altres a fer cavalcades y cativarse com a enemichs capitals matant-se en batalles los uns als altres' ${ }^{12}$.

Pero el reajuste de los límites políticos no conllevó uno paralelo de los eclesiásticos. $Y$ mientras los territorios del reino de Valencia ultra Sexonam quedaron bajo la soberanía de la Corona de Aragón, siguieron dependiendo en el orden espiritual del castellano obispo de Cartagena ${ }^{13}$.

Por tanto, es en esta falta de coincidencia entre los límites civiles y eclesiásticos donde hallamos el origen de las reclamaciones episcopales oriolanas. Desde este momento, ni el capítulo de la iglesia de El Salvador, ni el Consell de Orihuela, bien por separado, bien conjuntamente - lo que ocurriría la mayoría de las ocasiones-, cejarían en su empeño de lograr la creación de un obispado con sede en la ciudad del Bajo Segura, y cuya diócesis estuviese conformada por los territorios del reino de Valencia que muy a disgusto se hallaban sometidos a la autoridad episcopal murciana ${ }^{14}$.

11 DEL ESTAL, J.M., Orihuela, de villa a ciudad, Alicante, 1996, pp. 39-41. La Procuración ha sido analizada recientemente por CABEZUELO PLIEGO, J.V., Poder público y administración territorial en el Reino de Valencia, 1239-1348. El oficio de la Procuración. En prensa. Alicante, 1997.

12 Archivo de la Catedral de Orihuela, Actas Capitulares, libro I «Papeles y bulas conducentes a la catedralia", ff. 267v-268.

13 BELLOT, P., Anales de Orihuela (siglos XIV-XVI), Orihuela, 1956, v. Il, p. 33. Mosén Bellot califica de "descuido" el hecho de que, en las negociaciones de Torrellas y Elche, Jaime II no completara la partición del territorio con un deslinde de obispados, "Costó este descuido innumerables ducados, infinitas pesadumbres, muchos entredichos y descomuniones, que como casi todos los obispos eran castellanos, por cualquier mínima ocasión echaban mano a las armas espirituales...".

14 Sobre los territorios que pertenecian a la diócesis de Cartagena, puede consultarse la obra de MERINO ÁLVAREZ, A., Geografía histórica del territorio de la actual provincia de Murcia, Madrid, 1915, p. 54. Por otra parte, diferentes factores motivaron las reivindicaciones separatistas oriolanas: el abandono pastoral de las tierras valencianas situadas al sur de Jijona por los prelados castellanos, o las disciminaciones y abusos que habian de sufrir los pobladores de dicho territorio cuando tenían que personarse en la curia episcopal para tratar cuestiones de jurisdicción eclesiástica. 
Tenaz aspiración independentista que, como comprobaremos, compartieron y fomentaron los diferentes monarcas de la Corona de Aragón, entre otros motivos, para evitar los frecuentes incidentes fronterizos murciano-oriolanos y, sobre todo, el hecho de que las rentas eclesiásticas de sus territorios más meridionales pasaran a acrecentar las arcas del obispado de Cartagena, una Iglesia castellana ${ }^{15}$.

De cualquier forma, hay que hacer notar que Orihuela no fue la primera población elegida para ser la sede episcopal de la pretendida diócesis. Aunque el proyecto no prosperó, el mismo Jaime II, el 22 de noviembre de 1317, propuso al papa Juan XXII la erección de un nuevo obispado con capital en Játiva ${ }^{16}$. Tras este fracaso inicial, las futuras solicitudes de los reyes aragoneses a la Sede Apostólica ya sí fueron encaminadas hacia la consecución del título episcopal para el oppidum del Bajo Segura.

Jaime II falleció el 2 de noviembre de $1327^{17}$. Le sucedió su hijo, Alfonso IV el Benigno, tras renunciar en su favor el primogénito, su hermano Juan, para profesar en la orden militar de San Juan de Jerusalén. Alfonso, viudo de $\mathrm{D}^{\mathrm{a}}$. Teresa de Entenza y de Antillón, contrajo segundas nupcias con Dạ. Leonor de Castilla. Ésta siguió una política "farnesiana", intentando conseguir privilegios para sus hijos en perjuicio del heredero al trono, el que más tarde sería Pedro $\mathrm{IV}^{18}$. Al primero de ellos, el infante $\mathrm{D}$. Fernando, el rey le donó, por real privilegio dado en Valencia el 28 de diciembre de 1328, las poblaciones de Tortosa, Albarracín, Orihuela, Callosa de Segura, Guardamar, Alicante, Monforte, Elda, Novelda, La Mola y Aspe, creándose así el señorío de Orihuela ${ }^{19}$.

Los años siguientes no fueron años tranquilos para los territorios del señorío. D. Fernando los indujo a participar en todas sus campañas belicosas, tanto contra su hermanastro, Pedro IV el Ceremonioso, en un primer momento, como contra Pedro I el Cruel, rey de Castilla, en la guerra que enfrentó a ambos monarcas ${ }^{20}$.

Los primeros roces de la iglesia oriolana con Murcia que hemos logrado constatar tuvieron lugar en el año 1353. El arcipreste, Jaime de Bobadilla, acusó ante el justicia y los jurados de la villa a Jaime Maestre — racional del infante- de haber vendido los censales que se habían de destinar a la compra de cirios y el mantenimiento de las lámparas, a las capellanías y a otras obras pías, para cobrar 5.000 sueldos que por amortizaciones debía dicha iglesia. Las citadas autoridades seculares declararon no

15 VILAR, J.B., Los siglos XIV y XV en Orihuela. Historia de la Ciudad de Orihuela, t. II, Murcia, 1977 , p. 370. J.B. Vilar expone estas mismas razones pero afirma, en nuestra opinión erróneamente, que las tensas relaciones de frontera «no lograron relegar por completo la cordialidad que tradicionalmente presidió las relaciones de Murcia y Orihuela".

16 MANSILLA, D., "La reorganización eclesiástica española del siglo XVI. I. Aragón-Cataluña", en Anthologica Annua, 4 (1956), p. 102.

17 GISBERT Y BALLESTEROS, E., op. cit, t. II, p. 52.

18 CHIARRI MARTÍN, M.L., Orihuela y la guerra de las Germanías, Murcia, 1963, p. 19.

19 El texto íntegro de la donación lo podemos consultar en GISBERT Y BALLESTEROS, E., op. cit., t. II, pp. 696-701.

20 Sobre este enfrentamiento es indispensable consultar la obra de CABEZUELO PLIEGO, J.V., La Guerra de los Dos Pedros en tierras alicantinas, Alicante, 1991. 
tener jurisdicción sobre el referido racional. La respuesta no agradó al clero oriolano, de modo que elevó una queja al obispo, Alonso de Vargas. Éste, tras analizar el cariz de la situación, lanzó contra la villa el que sería el primero de una larga serie de entredichos que contra ella serían fulminados a lo largo del tiempo de dependencia de los prelados cartaginenses. El período de irregularidad espiritual duró poco, pues la diligente intervención del baile general, Juan Ximénez de Perencisa, consiguió que el provisor del obispado, Juan Martínez de Canales, alzara la censura ${ }^{21}$.

No obstante, es dentro del marco de la Guerra de los Dos Pedros donde hallamos el primer rompimiento abierto de Orihuela con el supraescrito obispo de Cartagena, Alonso de Vargas. Hacia mediados de 1357, al conocer que Pedro el Crue/ hacía preparativos para atacar Orihuela, el Consell dispuso, entre otras medidas defensivas, la reparación de los muros y baluartes. Y como el obispo se negó a construir el lienzo de muralla próximo al granero episcopal del diezmo, haciendo caso omiso a las peticiones de la villa, la citada corporación municipal decidió actuar por su cuenta y riesgo, y procedió a la incautación de trigo del prelado por valor de 3.000 sueldos, cantidad que sería suficiente para cubrir los gastos de la obra.

Agravió al obispo esta iniciativa por lo que, además de quejarse ante D. Fernando, lanzó contra toda la población un nuevo entredicho. Decidió el señor de Orihuela que lo mejor era complacer al obispo, y por ello ordenó al Consell que devolviera al prelado la especie incautada para que así fuese conmutada la pena. Pero tan pronto marchó el infante a su villa de Albarracín, volvió el Consell a instar a Alonso de Vargas a que sin más demora sufragase la construcción del tramo de muralla que le correspondía pues, de no hacerlo, le secuestrarían todas sus rentas. Al no obtener respuesta favorable del mitrado, los oficiales concejiles hicieron efectiva su amenaza. Conscientes de la imperiosa necesidad de obtener dinero para reforzar las defensas, incautaron todo el grano episcopal y lo vendieron en la misma villa. Indignado el pastor con tal actitud de su rebaño, protestó alegando que la mercancía podría haber sido vendida fuera de Orihuela con mayores beneficios, pero se abstuvo de poner entredicho ${ }^{22}$. No finalizaron ahí, por supuesto, las diferencias entre el prelado y Orihuela. Tal fue el talante de Alonso de Vargas que llegó a tomar las armas contra sus diocesanos valencianos y participó en el cerco y asalto de Orihuela23.

Si bien la conquista de Orihuela por los castellanos, acaecida el 7 de junio de 1365, fue un hecho de gran relevancia en el transcurso de la contienda de los reyes homónimos, aún tuvo mayor trascendencia si tenemos en cuenta el favor que ganó la

21 GISBERTY BALLESTEROS, E., op. cit, t. II, pp. 93-94. Según Gisbert, este suceso hizo surgir en la mente de los oriolanos la idea de obtener su separación de la diócesis de Cartagena. No les bastaba con arrancar la concesión de un vicariato, que les permitiera zanjar sus cuestiones de índole eclesiástica con independencia de la autoridad del obispo murciano.

22 Archivo Municipal de Orihuela, Libro de Cartas Reales, 1358, f. 66. Esta cuestión es tratada además en VILAR, J.B., Los siglos XIV y XV..., pp. 370-371; en GISBERT Y BALLESTEROS, E., op. cit., t. II, p. 140; y en GEA MARTÍNEZ, J.R., Páginas de la Historia de Orihuela. El pleito del Obispado. 1383-1564, Orihuela, 1900, pp. 10-11.

23 DÍAZ CASSOU, P., op. cit., pp. 37-38. 
villa, por su comportamiento valeroso y fiel, en la consideración de los sucesivos monarcas de la Corona aragonesa, que casi siempre escucharon con buena disposición sus reivindicaciones episcopales ${ }^{24}$.

Por otra parte, antes de proseguir el relato de las tensas relaciones entre los prelados cartaginenses y el clero y el pueblo oriolanos, hemos de destacar que hacia mediados de 1363, y a instigación de Pedro IV el Ceremonioso, fue asesinado el infante D. Fernando. Y por real privilegio datado el 10 de julio del año siguiente, el citado rey anexionó Orihuela y su hinterland a la Corona de Aragón y juró que jamás volvería separarla de ella. Y aún más, el 10 de septiembre de 1366, en virtud de otro privilegio dado en Barcelona, el mismo Pedro IV estableció que, en lo sucesivo, dicha villa ya no podría ser sometida a la jurisdicción del gobernador de la ciudad de Valencia, ni a la de ningún otro, sino que dispondría de un gobernador propio e independiente. Nacía así la gobernación del Reino de Valencia ultra Sexonam, con capital en Orihuela ${ }^{25}$.

El único incidente digno de destacar, a nivel espiritual, entre Orihuela y el siguiente obispo de Cartagena, Nicolás de Aguilar, fue la fulminación de un nuevo entredicho contra la citada villa en el año 1371 . El referido prelado ordenó a 120 oriolanos que acudieran a Murcia, a la curia episcopal, a testificar. El Consell les mandó que no fuesen porque iba contra los privilegios de la villa el hecho de que vecinos de ella tuviesen que ir a prestar declaración a reino extraño. La reacción del obispo no se hizo esperar: excomulgó a los 120 reclamados, citó a otros 300, y lanzó el interdicto. El Consell envió a la corte a un procurador llamado Juan de Fontes para que informase a Pedro IV de las censuras fulminadas contra los oriolanos.

La representación de Fontes tuvo éxito pues poco tiempo después, ya en 1372, llegó a la villa del Bajo Segura Fr. Francisco Mateu, inquisidor de la Corona de Aragón, quien, ejerciendo como tal, realizó diversos procesos. Y además, el rey ordenó al gobernador, Bernardo de Senesterra ${ }^{26}$, que se incautasen bienes del obispo por el valor de los daños que, contra los fueros, éste había infligido al Consell. Y así procedió el representante real.

Conocedor de tal acción, el deán y vicario general del obispado, Pedro Puixmarín, amenazó con excomulgar al gobernador a menos que restituyese la cantidad apropia-

24 GISBERT Y BALLESTEROS, E., op. cit., pp. 265-278 ofrece una completísima descripción del cerco de Orihuela. Por otra parte, el privilegio real dado en Barcelona el 18 de julio de 1380 por Pedro IV - Hamado el Morabatin - nos pone de manifiesto con todo lujo de detalles, algunos de ellos incluso escabrosos, la fiereza y la valentía de los oriolanos a la hora de hacer frente a los ataques castellanos. Este privilegio sería presentado como mérito en la mayoría de las peticiones del capítulo de El Salvador y el Consel/ de Orihuela relacionadas con sus aspiraciones episcopales. Podemos hallarlo íntegro o en alusiones en el Archivo de la Catedral de Orihuela, Actas Capitulares, libro I "Papeles y bulas conducentes a la Catedralia", ff. 75-76v, 267-267v, y libro II "Copia del proces de la Cathredal de la Esglesia de Oriola", ff. 10v-13, 231v-232, $247 \mathrm{v}$ y 259v-261; y editado, comentado y traducido en GISBERT Y BALLESTEROS, E., op. cit., pp. 385-394.

25 Se conserva una copia de este último privilegio en el Archivo de la Catedral de Orihuela, Actas Capitulares, libro I "Papeles y bulas conducentes a la Catedralia», ff. 71v-74v.

26 GISBERT Y BALLESTEROS, E., op. cit., t. II, cap. VI, pp. 311-332 publica un "catálogo de gobernadores ' del reino de Valencia más allá de Jijona. 
da, pero no pudo hacer efectivo su ultimátum porque el obispo se hallaba fuera de la diócesis, en Avignon - localidad en la que residía la Curia Romana-. No obstante, temiendo el gobernador que «en las parroquias de Murcia le descomulgarian cada dia tres veses a el y a su teniente y Assessor y a Juan de Fontes", le escribió al provisor y vicario general explicándole que, por la fidelidad que le debían al Ceremonioso, no podría devolverle las rentas hasta que todos los oficiales reales fuesen absueltos. A lo que Puixmarín contestó que «a iure y por decreto sinodal estavan descomulgados y la tierra entredicha si no restituian al obispo los frutos que le havian llevado".

Aunque mosén Bellot —fuente utilizada ${ }^{27}$ — no recoge el final de la cuestión, suponemos que se llegó a un acuerdo antes del siguiente entredicho, que se produjo en 1375.

Tras el fallecimiento de Nicolás de Aguilar, fue electo obispo de Cartagena el francés Guillén Gimiel quien casi de inmediato, el 7 de mayo de ese mismo año, presidió un sínodo en el que se aprobaron varias constituciones entre las que destacaba una que hacía referencia a "los que usurpan y toman los diezmos y los derechos de la eglesia», en clara respuesta a las frecuentes apropiaciones de los bienes episcopales que solía realizar el Consell oriolano ${ }^{28}$.

El entredicho referido se produjo a raíz de la llegada a Orihuela de Antón Dolcet, clérigo beneficiado en la iglesia de San Jorge de Lorca. Éste debía entregar ciertas cartas del mitrado al arcipreste de El Salvador. No obstante, por causas que se desconocen fue detenido y encarcelado en las prisiones del Consell.

Enterado Gimiel de los hechos, realizó diversas gestiones para conseguir su liberación; pero al resultar vanas todas sus instancias, decidió excomulgar a quienes habian intervenido en la detención del prebendado y lanzar el entredicho sobre la villa.

Ignorando el motivo de tan grave censura, el Consell envió a Murcia a un procurador llamado Ruidoms para que se entrevistase con el prelado. El francés le respondió que no le había agradado tener que fulminar a la villa con el interdicto, pero que se había visto obligado a ello porque el justicia oriolano había metido en prisión a un tonsurado. Y añadió que a menos que lo soltasen, no alzaría la censura.

Tras conocer la posición del obispo, el Consell le envió dos nuevos emisarios, Guillem Belloch y Vicente Zaragoza, quienes le manifestaron que el justicia no tenía preso a ningún tonsurado, y que aún en el caso de tenerlo, el pueblo no tenía culpa de ello.

Tampoco atendió en esta ocasión el obispo cartaginense a la citada petición. $E$ intentando agravar la situación, prohibió a los murcianos que tuviesen trato con los excomulgados. No obstante, sin temor a las condenas espirituales, el concejo murciano desoyó las amenazas del prelado, alegando en su contra las órdenes del rey Enrique II de Castilla de que mantuviesen relaciones pacíficas con los súbditos de la Corona aragonesa, con vistas a favorecer los intereses mercantiles de la ciudad ${ }^{29}$.

No conocemos cómo terminó la cuestión pero, por otra parte, es realmente interesante comprobar que, ya en esta época, los intereses temporales se sobreponían a los espirituales, y que importaba más a la población oriolana la defensa de sus intere-

27 BELLOT, P., op. cit., vol. II, cap. V, p. 466.

28 DÍAZ CASSOU, P., op. cit, p. 41.

29 BELLOT, P., op. cit., vol. II, p. 474. VILAR, J.B., Los siglos XIV y XV.., pp. 371-372. 
ses y aspiraciones episcopales que las frecuentes y largas temporadas de privación de servicios religiosos ${ }^{30}$.

El desarrollo del pontificado de Guillén Gímiel fue poco pacífico; las fricciones y los agravios entre ambas partes estuvieron a la orden del día. Aún en 1383, último año del francés al frente de la mitra cartaginense, se produjo un hecho de amplias repercusiones $^{31}$.

En las Cortes celebradas en Monzón ese año, el síndico de Orihuela, Berenguer Vimbaldi, solicitó a Pedro IV que concediese a Ginés Silvestre un beneficio en la iglesia de Santiago de la referida villa. El monarca, teniendo en consideración los heroicos servicios que le prestara el caballero Domingo Silvestre - padre del tal Ginés-en la pasada guerra con Castilla, accedió a la petición.

Entonces, Silvestre pretendió permutar dicha prebenda con un clérigo de Murcia, que había obtenido otra en la parroquia de San Miguel. Pero mientras el murciano accedió sin ningún impedimento al mencionado beneficio de la iglesia de Santiago, Silvestre sí halló dificultades a la hora de completar la permuta. Después de que se le negara la posesión de la prebenda, tuvo que huir de la ciudad vecina y rival porque lo quisieron matar al conocer su condición de oriolano.

Sumamente indignado, el Consel/ de Orihuela se puso de acuerdo con el de Alicante, y ambos organismos comisionaron respectivamente a Francés Fabriques y a Jaime Franco para que marcharan a la corte a presentar al monarca sus quejas y reivindicaciones. $Y$ así hicieron, y con el apoyo del influyente D. Guillén de Rocafull, pidieron a Pedro IV que suplicase al pontífice Bonifacio IX la desmembración de la gobernación del reino de Valencia ultra Sexonam de la jurisdicción de la diócesis de Cartagena y la erección de un nuevo obispado con sede en Orihuela ${ }^{32}$.

Posteriormente, fueron enviados a la corte regia y a Roma, con la misma pretensión, nuevos síndicos del capítulo de El Salvador y del Consell de Orihuela: Pedro de Galbe, Jaime de Rocamora, Francisco Desprats, mosén Jaime Torres, y muchos otros. Pero no consiguieron resultados que colmaran sus expectativas.

Aún tendría que pasar la población del Bajo Segura por muchas vicisitudes, como la erección de la iglesia de El Salvador en Colegiata en 1413, o dos intentos fracasados de crear el obispado propio e independiente, en 1442 y 1510. Pero Orihuela no encabezaría su propia diócesis hasta el 14 de julio de 1564, fecha en que Pío IV atendería la suplicación de otro monarca, éste ya de España, Felipe II, el Rey Prudente.

30 El entredicho eclesiástico conllevaba privaciones tan notorias como la imposibilidad de cumplir con el precepto dominical, de recibir los sacramentos, de contraer matrimonio, o de dar sepultura a los muertos en suelo sagrado.

31 Esta controversia es analizada por los diversos autores. GEA MARTÍNEZ, J.R., op. cit., pp. 1112. VILAR, J.B., Los siglos XIV y XV.., p. 372. GISBERT Y BALLESTEROS, E., op. cit., t. II, p. 411. CHIARRI MARTÍN, M.L., op. cit., p. 27.

32 BELLOT, P., op. cit, vol. I, p. 130, reproduce la súplica de los procuradores oriolanos: «ltem, Señor, per quant son molts y intolerables los agravis que rebem dels bisbes de Cartagena axi en temps de guerra com en temps de pas, placia a Vuestra Magestat si es pot intercedir ab lo papa que dividixca esta partida del reyne del bisbat de Cartagena y intituexca en ella un bisbat y que lo que sera dat pera governarlo se nomene bisbe de Oriola". 